\title{
Conclusion: The Persistence of Media Resistance
}

\begin{abstract}
The final chapter compares and contrasts media resistance across media, historical periods and national borders. While there is strong continuity in the values that resisters perceive to be at stake, there are also profound changes. One important change is that media resistance increasingly has moved from the political to the personal domain. Three explanations are offered for how media resistance is sustained as a strong cultural current: media resistance is flexible and adaptable, media resistance is connected with other great narratives of hope and decline, and media resisters keep a distance from (empirical) media research.
\end{abstract}

Keywords Media resistance $\cdot$ Media protest $\cdot$ Moral panic $\cdot$ Media panic . Media studies

\section{A Great Failure! A Great Success!}

"Nowadays, the refrain is that 'there's no stopping our powerful new technologies'," the writer Jonathan Franzen observes in The Guardian (2013). In his view, “[g]rassroots resistance to these technologies is almost entirely confined to health and safety issues, and meanwhile various logics - of war theory, of technology, of the marketplace - keep unfolding automatically." Franzen laments that "we find ourselves spending most of 
our waking hours texting and emailing and Tweeting and posting on colour-screen gadgets because Moore's law said we could," and that we are told that "passion' for digital technology" is more important than the skills taught in the humanities.

Franzen's observations sum up what many media sceptics are feeling in dark moments: Resistance to new media and technologies is a lost cause. It is difficult to find a path of action for media resistance, the time spent on media keeps rising and online and social media are becoming ubiquitous and penetrating. Yet, as shown in the book, expressions and actions of media resistance do not go away. Media-resistant sentiments continue to spark off political and cultural debates, seep into fiction plots, inspire manifestos, sell books, influence lifestyle choices and get conversations going.

This book is based on a selection of cases and examples, invariably other cases and examples could have been chosen. There is an enormous amount of material to choose from, and other material may have led to other observations. Nevertheless, the selected material has illuminated media resistance across historical periods, geographical areas and media platforms. In this final chapter, I summarize the main observations as to what is at stake and what to do, ending with a discussion of how resistance is sustained. Throughout the chapter, I also refer to implications for media scholarship, although a thorough discussion of the relationship between media resistance and media studies would need a book of its own.

\section{Shifting Arguments, Recurring Concerns}

Six recurring concerns were identified in the first chapters and have been used to discuss resistance throughout the book: morality, culture, enlightenment, democracy, community and health. These values continue to motivate resistance and influence the way arguments and metaphors are constructed, yet, while some arguments remain consistent, the nature of others have changed in the view of social and media transformations.

The argument that media and popular culture undermines morality is a classic position, which has justified criticism and restrictions throughout media history. Protests have erupted in many countries against content and functions perceived to be amoral (often sexual and violent) in literature, cinema, comics, television, videos and online media. The concern for copycat effects, that the young and vulnerable would imitate 
bad behaviour, is expressed in progressively severe metaphors such as "education for crime" (cinema), "education for terror" (comics) and "murder simulators" (games). The risks of online addiction and exploitation are expressed suggestively as being "caught in the net" and "tangled in the web" (Young 1998, 2000).

Moral arguments are consistent in the sense that subsequent generations of protesters have used similar metaphors and phrases to describe subsequent generations of media. Professionals and activists who react to the media on moral grounds often use strong and violent metaphors, prompting media liberals and scholars to describe them as panicky and irrational (Ch. 1). Clearly, the moral arguments against the media have become less pervasive, as moral norms are changing there is a greater tolerance for activities previously deemed amoral. However, moral campaigners can look back on a centuries-long tradition of protest, and can argue with some justification that from their perspective, the warnings issued have not been that far-fetched; even if the copycat argument lacks empirical proof, the tremendous proliferation of mediated sex, violence and lewd content defy even the most dystopic predictions. This is only one reason why the liberal use of labels such as "moral panic" and "media panic" to describe resisters may be inadequate; moral protesters may be entirely rational in their judgements even if they go against the social consensus. If the purpose is to understand why some react to the media, the use of a predetermined panic-label may not be the best starting point.

The concern for culture, and the belief that the media should show "the best" in different genres, is another fundamental position in media resistance and scepticism, spawning a range of powerful metaphors describing disgust and disappointment. Early mass culture was described metaphorically as "thrash," "garbage," "pulp," and later television, particularly commercial television, were criticized for driving culture towards the "lowest common denominator," leading to "Wall-to-Wall Dallas" (McKee 2006). Television was metaphorically named "the idiot box" and online and social media are criticized for leading to "dictatorship of idiots" (Keen 2008). The concern about the public's "writing diarrhoea" in the eighteenth century (Krefting et al. 2014) parallels concern that "The Internet is today's toilet wall” (Sørensen 2010), hitting a new low in cultural standards.

Like the morality argument, also the argument that popular media undermine culture is consistent and represents a "common sense" approach in wide circles, although the argument has lost credibility 
among intellectuals and cultural consumers alike (Storey 2009, 33, ch. 2). One reason is the increased sophistication of mass culture itself; the explosion in new forms of youth culture from the 1960s, and the expansion of middle culture appealing to an increasingly educated postwar public, blurred the distinction between mass and high culture (MacDonald 2011; Menand 2011). Scholars within media and cultural studies have also played a part in rehabilitating popular culture from "thrash" to "art," by identifying complexity and originality in products such as cinema films, popular literature and television series. With the current growth in amateur cultural expressions online, it is interesting to note that mass media and mass cultural products are increasingly defended, they are seen to represent quality and professionalism in stark contrast to user-generated amateurism. Even mainstream television culture is deemed more worthy of protection in an era where anyone can publish cultural expressions online (Ch. 5).

With each shift in communicative mode, concerns have been expressed that the new mode - and the cumulative push of too many media - undermine enlightenment. The enlightenment arguments, and particularly the contention that media threaten education and learning, are less consistent across media and historical periods than the concerns for morality and culture, on the contrary, developments in widely different directions have, over the course of time, been pointed to as having similar negative outcomes. For example, many new media have been criticized for undermining educational aptitude because they induce passivity: the expansion of popular literature and comics brought concern about "passive reading," radio brought concern with "passive listening," and television viewers were caricatured as passive "couch potatoes" (Chs. 2 and 4). With online and social media, there is the opposite concern; users are not seen as passive, but rather hyperactive and restless, metaphorically described as developing "a juggler's brain" (Carr 2010, see Ch. 5). The criticism in the latter case blames the constant interruptions and abundance of information in social and online media for undermining concentration, and see this as more detrimental than the flow-character and linearity of the mass media.

Again, what makes the arguments converge among those concerned with protecting enlightenment and learning is a defence of earlier media forms, in particular the defence of print culture. Two perspectives unite the defenders of print and literary culture against new modes as discussed in this book: the idea that printing was essential for modernity, 
enlightenment and the scientific revolution, and thus for civilization as we know it, and the idea that reading and writing is a superior mode of learning and reflection (Chs. 3,4 and 5). As challenges to the businesses and institutions of print culture - newspapers, book publishers, literary institutions, the humanities - become more visible, the professions who serve and sustain them - authors, journalists, educators, writers - have found a line of defence that is not necessarily effective, but at least resonate with widely held beliefs that print culture is essential to preserve.

The use of cinema, radio and print for propaganda purposes in the early twentieth century led to warnings that media would undermine democracy. The danger of authoritarian takeover with the help of the mass media is vividly portrayed in fictional accounts such as Brave New World, Nineteen Eighty-Four and Fabrenheit 451, and in metaphors related to mind control and media's "hypnotic" abilities. In the post-war era, the doomsday predictions became less pronounced, but television was still seen to impair democracy by turning politics into entertainment. Among many of those who disliked television, digital media and Internet was met with high hopes; the Internet was predicted to be "a platform for pursuing the truth," but hope turned into disappointment as celebrated "social media revolutions" failed and Internet was used to promote authoritarian viewpoints. Metaphors such as "filter bubble," "echo chamber" and "egocasting" (Ch. 5) all point to new concerns about political extremism and social fragmentation, so do also emerging concerns that we are entering a "post-truth" era dominated by mediated lies and "fake news".

The disappointment that media and communication platforms do not fulfil their prescribed democratic role has been profound for scholars and activists, including intellectuals drawn to journalism, media or Internet studies with an idealistic attitude towards media's democratic potential. Without necessarily promoting media resistance, the argument that media undermine democracy is perhaps the one concern most fuelled by disappointment. In addition, this type of disillusionment has, for some, led to a defence of traditional mass media. In contrast to algorithm-based online services, established mass media such as newspapers, public service broadcasting or even national commercial broadcasting are defended because they are seen to adhere to editorial principles, bring citizens into a common sphere and act as a buffer against extremism.

The concern that media undermine community was fuelled by mass society theories in the early 1900s; along with industrialization and urbanization, the emerging mass media was seen to undermine interpersonal 
bonds and leave societies volatile (Ch. 2). The concern that media destroys community represent an interesting antidote to the widespread argument that mass and social media bring people together by giving them something to talk about and means of keeping in touch. Critics point instead to the increasing differentiation of products and services in the media industries, which provides each generation with enhanced opportunities to personalize their media consumption and block out what is going on in their physical and social surroundings. Print and mass media provided citizens with common stories, but also windows of escape from other family members and local figures of authority. Cinema tempted people out of their homes and into a community of sorts, but a community of darkness, different from sites of politics, learning or worship. Radio and television brought people home again, but were criticized for shifting attention away from local civic engagement. With increased mobility, social and online media can be used anywhere, but concerns are raised that people are, metaphorically speaking, "alone together" (Turkle 2011).

As proliferation of media intensify, the main challenge defined by critics and sceptic is to sustain a public conversation and prevent new media from invading all personal and public spaces. In doing so, the use of older and more established media is again held out as a remedy: book reading, joining a book club, attending a public lecture, watching a film, playing board games or gathering in front of a television set, are all seen as means to combat isolation and sustain small and large communities. While other concerns in media resistance have become less prominent with time, the concern that media undermine community increasingly occupy centre stage; interestingly, this is a dominant theme in several feature films depicting the implications of social and online media, including Disconnect and $\mathrm{Her}$ (Ch. 6). A key argument in this book has been that with online and social media, some forms of resistance are becoming more acceptable and widespread. Resistance is less a case of "us" pointing out that "their" media use is bad; in an era of ubiquitous media, we all need a measure of resistance to prevent media invasion.

Early mass media brought strong warnings about health risks: concern for eyesight, mental disorders, fire in cinema theatres, and an array of other physical and mental problems. Television viewing was likened to drug use, life in captivity and diminishing capabilities; with social and online media there are warnings of autism, attention deficit disorder and hyperactivity. Many media resistance metaphors are health-related, early metaphors include references to disease and epidemics, there is talk of "writing 
epidemic" and "writing diarrhoea," "nickel delirium" and "contagion," and television is described as "The Plug-In-Drug." Metaphors of "detox" and "fasting" describe ways to regain control and prevent media overload.

The metaphors used in media resistance are strongly linked with narratives surrounding health and the body in different historical periods. Early resistance reflects the struggle to combat lethal infections and epidemics, whereas in later eras, the concern has shifted to how individuals can improve their health through diet, exercise and control of toxic substances. While "the slender, well-trained body ideal was increasingly exploited in the mass media and advertising" (Sundin and Willner 2007, 202), obesity and health problems such as muscular conditions and sleep deprivation, have increasingly been linked with media-induced passivity and excessive use of screen media. In a sense, the arguments about media undermining health have come full circle; while early warnings about media health risks seem extreme and exaggerated in retrospect, the increased use of media and communication devices adds weight to arguments that overuse of today's media may indeed threaten health. In a culture emphasizing self-discipline, an intense and voluminous engagement with media may be equalled to drinking too much, smoking too much or eating too much, and self-restrictions and abstention can be used to regain a measure of control. In addition, refraining from media, or at least demonstrating self-discipline, is a great way of communicating identity as a healthy human being.

\section{Fierce Resistance, Struggling Activists}

It is not easy to find a path of action for media resistance. Forms of action can be placed on a continuum, as pointed out in the introduction, from legal and political protests to self-restrictions; and although a variety of methods have been proposed and used, protesters and sceptics have struggled to find methods that are effective to restrict and control media. In this book I have discussed cases and examples from the US and Europe, most notably from the UK and Scandinavia, across three phases in media history. To what degree have the forms of resistance varied or changed across media, historical periods and geographical settings?

In the era of early mass media, in the 1800s and 1900s, forms of action were similar from one campaign to the next and across national boundaries. Both in Europe and the US, protesters largely campaigned for legal, political and institutional control and censorship, while institutions such as 
churches, schools and libraries were gatekeepers for keeping out undesirable material. Protesters relied on a common arsenal of methods such as public meetings, petitions, pamphlets and letters to the press, alliances built with experts and professional bodies, and appeals directed at legislators, producers and distributors. Campaigners travelled across boundaries and some activists, such as the anti-comic campaigner Fredric Wertham, had great influence across the Atlantic (Ch. 2).

With the emergence of broadcasting and television, paths of resistance diverged. In Europe, state-owned broadcasters became responsible for elevating morality, culture and enlightenment, whereas in the US, educational and cultural interest lost out to commercial forces (Ch. 2). The evolvement of television as a commercial institution prompted stronger anti-television sentiments in the US; inspired by writers and activists such as Neil Postman and Marie Winn, a movement emerged with the goal of getting rid of television step-by-step (Ch. 4). While European critics could direct their protests to legislators and policy makers, the limited role of government in regulating US media made it more difficult to influence broadcasting through the democratic process (Croteau and Hoynes 2012, 81). The TV-turnoff movement instead drew inspiration from the increasing use of consumer boycotts in the US in the 1990s, like other boycotts a television turn-off was a means "to achieve certain objectives by urging individual consumers to refrain from making selected purchases in the marketplace" (Friedman 1999, 4).

With online and social media, the methods of action converge again, reflecting political and economic liberalization and the increasingly global nature of communication platforms. Resistance to social and online media bear many similarities to television resistance; writers issue dire warnings and use potent metaphors to predict social ills, yet, there are notable underlying ideological shifts. Writers are highly self-reflexive, much space is used to protest or dismiss pejorative labels and demonstrate that protesters are not moralists, luddites, laggards or cultural pessimists. Some still advocate regulation, but acknowledge that most (negative) aspects of social and online media would have to be dealt with through other means. Even if there are still examples of mass rallies against Internet and social media, the main method proposed is to start or take part in a conversation where the trouble with media can be aired in public.

In addition to conversation, many writers and activists encourage selfregulation; in the years after the millennium, there has been a proliferation of media self-help guides and detox confessionals. Self-help is often 
perceived as being more pronounced in the US, but self-help has also become an integrated element of European and Scandinavian welfare policy; self-help and self-control are measures to relieve an overloaded state (Madsen 2014, 19-20). The aims of conversation and self-regulation are often linked; it has become common to engage in a period of media fasting and then report and converse about it in print or digital media. The mediation of media resistance is by itself an interesting topic; in this book, I have discussed genres as different as detox confessionals, media self-help guides, media resistance manifestos, and feature films depicting media resistance. What is important is that acts of media resistance do not take place in isolation; they are networked and interlinked, emerge in different texts and genres, and resonate with cultural sentiments that cross borders and transcend historical phases.

Media resistance is often prompted by a professional reaction; an observation that media content or functions run counter to professional ethics. Educational, religious and medical professions were influential in early media protests. With the fragmentation and proliferation of resistance, it is difficult to identify specific professions that are more prominent. In the book, I have pointed out that many of those who argue that social and online media are invasive and detrimental are themselves early adopters, such as journalists, writers, innovators and "techies" who felt the early impact of always being online, and now issue strong warnings. In a sense, this is a new version of the repentant sinner who sees the light and writes a book about it, turning a personal conversion into a new missionary platform. It also illustrates a now familiar twist in media resistance, as once digital optimists are beginning to draw on arguments and metaphors familiar from centuries of media-critical protests.

\section{The Sustainability of Media Resistance}

In addition to what is at stake and what to do, a third key question runs through this book: How is media resistance sustained? Although the use of media and communication platforms continue to expand, the expression of media resistant sentiments show no sign of abating. Based on the material examined, I point, in conclusion, to three possible factors that can help explain sustenance: media resistance is flexible and adaptable, media resistance is connected with other great narratives of hope and decline, and media resistance is not to any great degree disturbed by the theories and findings of (empirical) media research. 
One explanation for the continuing presence of media resistance is its flexibility: media resistance is grounded in broadly shared values, but these values are adaptable. While objects of resistance change, values can remain consistent; as specific media, genres, technologies and functions become more accepted, the values can be used to legitimize a different type of concern related to a different medium. As pointed out, forms of action in media resistance have not only been flexible, but have engaged people from different segments of society, different professions and different nationalities. Seeing the media as a cause of harm is a position that is not really politicized; it can appeal to both to left and right, religious and nonreligious and a variety of professions. People who disagree on everything can still find themselves united in media resistance and scepticism; one can trust the media to convey something objectionable and disgusting that can bring life to lifeless dinner parties and stale water-cooler conversations. Media resistance also appeals to different sentiments; there is deep cultural pessimism and versions that are more upbeat, outdoorsy, self-satisfied and fun. Media resistance can be used to display a personal identity or a healthy lifestyle choice, and it can be profitable; a well-placed media resistance book can earn the writer a healthy wage and secure invitations to an endless round of column writing and conferences - as well as the advance on a second or third book.

Another factor explaining the continuing presence of media resistance is that it is connected with other great narratives of hope and decline. Narratives about the decline of humanities, science, language and history, narratives about "dumbing-down" and the decline of truth and reason, are spelled out in fiction and non-fiction pointing to the media as a cause of social ills. The narratives of warning and explanation are often nostalgic; observers have pointed out that both dystopian fiction and self-help, two genres that have given shape to media resistance arguments and actions, are conservative genres that may idealize the past (Baccolini 2003, 115; Madsen 2010,89). Yet, media protesters and sceptic are not necessarily anti-modernity as is often presumed. In the introductory chapter, I argued that the most prominent emotions in media resistance may not be panic and fear for the future, but disbelief, distrust and, above all, disappointment that a more promising future is becoming unattainable. These sentiments have surfaced generously in the material examined; there is distrust in the media for displacing rather than championing progressive causes, disappointment with intellectuals for succumbing to the lures of media instead of raising 
the standards of their profession, and disbelief as to how far media will go in their quest for audiences and profit.

However, media resistance is not just about disappointment, but also about hope. In the fictional as well as non-fictional works discussed in this book, there is not so much hope that media or society will really change, but some hope that each and every one of us can improve our lives by freeing ourselves from media entrapment. By replacing media use with non-media activities, it is suggested that one can build a future that is happier, more genuine and authentic, and based on more real-life encounters and pursuits.

A third and final explanation as to how media resistance is sustained is that it does not to any great degree depend on specific, detailed or even empirical evidence, and also remains at a significant distance from most academic media studies. In early protests against the mass media, there were strong expectations that expert evidence would come out in favour of resistance, that uncertainty and apprehension would give way to a solid scientific foundation. Although momentous amounts of research about harmful consequences of media have been initiated, evidence remains ambiguous and often do not fit the concerns of resisters; those critical and sceptical of the way media transformed society did not get precise answers from science. Some material discussed here draws - selectively on evidence from media effects research, some point to so-called medium theorists to argue that media's harm go beyond content and involve technology and functions, but, in general, the references to findings and perspectives from (empirical) media studies are scarce in the texts and arguments discussed in this book.

To the degree that books and articles touch on media studies and media experts, sceptics often express disappointment in what they see as the discipline's pro-media stance, and disappointment with the way media scholars have contributed to legitimize controversial media, genres and technologies. Although media criticism may well be taught in a media studies class, many media sceptics - and especially those who expressed resistance to television - have expressly distanced themselves from the efforts by media educators and scholars to teach media literacy. As one website cited in Chapter 4 points out, "If the 'off' button is the answer, then no media studies course will ever help students find it" (White dot $2000 \mathrm{~b}$ ). To the degree that media literacy is explicitly discussed, the sentiment expressed is that this does not point people towards nonmedia activities, but rather increase media fascination and use. 
Instead of being academic studies, the type of media resistance texts examined in this book can be seen as sense-making efforts; drawing selectively on facts, anecdotes, personal experiences and testimonies to connect the dots about media as a cause of social harm. In these narratives, fictional accounts may well be a more important frame of reference than experts' accounts. I have shown how many refer to dystopic classics such as Brave New World, Nineteen Eighty-Four and Fabrenheit 451, and how the narratives depicted in fiction and films, about the potentially bad implications of media, are part of the broader current that inspire arguments and actions of resistance. What also becomes clear after having read similar texts from different periods is that these do not, to any great degree, refer to each other. Even if many texts make many of the same claims, for example of how media destroys reading and print culture, and as such belong to a cumulative tradition, they rarely acknowledge the tradition or examine each other's predictions or assertions critically. Instead, they appear as stand-alone texts that often begin with a personal observation regarding one type of medium, and then selectively gather material that can support a broad assertion about destructive media.

I began this book with a story of my television-free childhood, and how I became part of a discipline that is criticized for being pro-media. While the aim here is not to assess this criticism, I have pointed to how theoretical and conceptual frameworks tend to imply that resisters and sceptics are irrational, backward, moralistic and simplistic. In conclusion, I would argue that there is nothing simple about media resistance, protesting, disliking and abstaining are just as complex as accepting, adapting and celebrating media. The book is an argument for further studies into media resistance, not only because it is worthwhile to understand the arguments and actions of resisters, but also because the study of media resistance teaches us something about the media, the study of media, and the choices and values perceived to be at stake in today's media environment.

Open Access This chapter is licensed under the terms of the Creative Commons Attribution 4.0 International License (http://creativecommons.org/licenses/ by $/ 4.0 /$ ), which permits use, sharing, adaptation, distribution and reproduction in any medium or format, as long as you give appropriate credit to the original author(s) and the source, provide a link to the Creative Commons license and indicate if changes were made. 
The images or other third party material in this chapter are included in the book's Creative Commons license, unless indicated otherwise in a credit line to the material. If material is not included in the book's Creative Commons license and your intended use is not permitted by statutory regulation or exceeds the permitted use, you will need to obtain permission directly from the copyright holder.

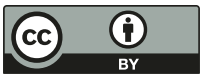

